\title{
Molecular Cloning, Expression and Purification of Truncated hpd Fragment of Haemophilus influenzae in Escherichia coli
}

\author{
Ava Behrouzi ${ }^{1}$; Saeid Bouzari ${ }^{2}$; Seyed Davar Siadat ${ }^{3, *}$; Anis Jafari ${ }^{2}$; Shiva Irani ${ }^{1}$ \\ ${ }^{1}$ Department of Biology, School of Basic Science, Science and Research Branch, Islamic Azad University, Tehran, IR Iran \\ ${ }^{2}$ Department of Molecular Biology, Pasteur Institute of Iran, Tehran, IR Iran \\ 3 Department of Tuberculosis and Pulmonary Research, Pasteur Institute of Iran, Tehran, IR Iran \\ ${ }^{*}$ Corresponding author: Seyed Davar Siadat, Department of Tuberculosis and Pulmonary Research, Pasteur Institute of Iran, Tehran, IR Iran. Tel: +98-9121442137, Fax: +98-2166492619, \\ E-mail:d.siadat@gmail.com
}

Received: September 2, 2014; Revised: November 14, 2014; Accepted: February 22, 2015

\begin{abstract}
Background: Nontypeable Haemophilus influenzae (NTHi) is a significant pathogen in children, causing otitis media, sinusitis, conjunctivitis, pneumonia, and occasionally invasive infections. Protein D (PD) belongs to the minor outer-membrane proteins of $H$. influenza. Moreover, it has been shown that this protein is one of the most potent vaccine candidates against the NTHi strain.

Objectives: In the present study, a new truncated form of PD was designed based on conserved areas, and recombinant truncated PD was expressed.

Materials and Methods: Truncated PD was designed using bioinformatics tools, and a $345 \mathrm{bp}$ fragment of the truncated hpd gene was amplified by polymerase chain reaction (PCR) from $H$. influenzae and subsequently cloned into the prokaryotic expression vector pBADgIIIA. In addition, for the expression of the recombinant protein, the pBAD-truncated PD plasmid was transformed into competent TOP10 cells. The recombinant protein was expressed with Arabinose. The expressed protein was purified by affinity chromatography using NiNTA resin.

Results: The cloning of PD was confirmed by colony-PCR and enzymatic digestion. Arabinose $0.2 \%$ was able to efficiently induce protein expression. The SDS-PAGE analysis showed that our constructed pBAD-PD-TOP10 efficiently produced a target recombinant protein with a molecular weight of $16 \mathrm{kDa}$. A high concentration of the recombinant protein was obtained via the purification process by affinity chromatography. The recombinant $\mathrm{PD}$ was reacted with peroxidase-conjugated rabbit anti-mouse immunoglobulins.

Conclusions: Our results showed that the recombinant protein produced by the pBAD vector in the Escherichia coli system was very efficient.
\end{abstract}

Keywords: Haemophilus influenzae; Recombinant Protein; Expression Vector; Ni-NTA

\section{Background}

Haemophilus influenzae is an important pathogen among infants and children. The serotype b strains of $H$. influenza (Hib) are a major cause of invasive infections (1). Nontypeable Haemophilus influenzae (NTHi) is a frequent commensal of the human nasopharynx but is also the common cause of respiratory tract infections such as otitis media, sinusitis, bronchitis, and pneumonia $(2,3)$. Although effective vaccines against the Hib strains have been used widely (4), they do not protect children against infections caused by the NTHi strains. The prevention of NTHI infections would provide considerable health and economic benefits. Thus, to develop a vaccine that protects against Hib and NTHi infections, several surface-exposed $H$. influenzae proteins such as pili and outer membrane proteins have been intensely studied (5-8). Vaccine candidate selection for $H$. influenzae is not easy because NTHi demonstrates extensive sequence and antigenic variation among the gene products interacting with the immune system such as outer-membrane proteins, adhesins, lipopolysaccharides, and secreted virulence fac- tors (9-12). One of the possible candidates of a vaccinogen is protein $\mathrm{D}(\mathrm{PD})(3)$. The antigenic conservation of $\mathrm{PD}$ and the role of this protein in the onset of $H$. influenzae infection suggest that PD is a candidate antigen for a vaccine to prevent nonencapsulated $H$. influenzae infection (13). PD manifests glycerophosphodiester phosphodiesterase activity, which is required for the transfer of choline from the host to the lipooligosaccharide of H. influenza (14-16). PD has also been proven to promote bacterial adhesion and internalization into human monocytes (17).

\section{Objectives}

The aim of the present study was to design a new truncated form of PD, to predict its B cell epitope, and to perform a protein structure modeling of the truncated form using bioinformatic tools with a view to assessing this constructed recombinant truncated PD as a vaccine candidate against $H$. influenzae. We used an expression system to produce this protein in Escherichia coli on a laboratory scale with the potential of production on an

Copyright (C) 2015, Ahvaz Jundishapur University of Medical Sciences. This is an open-access article distributed under the terms of the Creative Commons Attribution-NonCommercial 4.0 International License (http://creativecommons.org/licenses/by-nc/4.0/) which permits copy and redistribute the material just in noncommercial usages, provided the original work is properly cited. 
industrial scale. Further studies should be performed in order to evaluate the immune system.

\section{Materials and Methods}

\subsection{In Silico Design}

The truncated PD design was based on multiple sequence alignment of full-length protein sequences from several H. influenzae in the GenBank using ClustalW Multiple Sequence Alignment software, and the conserved areas of the PD sequence of $H$. influenzae were also selected. We used the immune epitope data base (IEDB) analysis resource (http://www.iedb.org) to identify the immunogenic epitopes of the H. influenzae PD. The modeling of the truncated protein was determined by I-TASSER website. The result of the modeling was validated and analyzed using protein structure analysis ProSa (https://prosa.services.came.sbg.ac.at/prosa.php) and SPDBV software Zscore (overall model quality). The Ramachandran Z-score (for calculating the quality of a Ramachandran plot) was calculated by using the SPDB Viewer.

\subsection{DNA Isolation}

Plasmid DNA was prepared by using a Qiagen plasmid DNA kit (Diagen GmbH, Dusseldorf, Germany) according to the instructions of the manufacturer. The genomic DNA of the H. influenzae strain ATCC49766 was prepared by using a genomic DNA extraction kit. Bacterial strains were routinely grown at $37^{\circ} \mathrm{C}$ in lysogeny broth (LB) broth or agar (Merck, Germany), supplemented with $50 \mu \mathrm{g} / \mathrm{mL}$ of ampicillin as required.

\subsection{Primers Design and Polymerase Chain Reaction}

The truncated hpd gene was amplified from the chromosomal DNA of the H. influenzae strain ATCC49766 via Polymerase Chain Reaction (PCR). Oligonucleotide primers were prepared on the basis of the published nucleotide sequence of the hpd gene from NTHi. The primers were designed based on the truncated hpd gene of the 86028NP strain (GenBank accession nos. CP000057.2) with NcoI and XbaI restriction sites (underlined), respectively. The sequences of the primers were as follows:

\section{F: 5'-CAT GCC ATG GAA GAA ACG CTC AAA G-3'}

R: 5'-GAT CTC TAG AGC ATT ATC AGG TTT GGA TTC TTC-3'

The PCR reactions were performed using the Eppendorf thermocycler. The PCRs were carried out in a $50 \mu \mathrm{L}$ volume containing $2 \mu \mathrm{LL}$ of DNA template, $5 \mu \mathrm{L}$ of $10 x$ reaction buffer, $2 \mu \mathrm{L}$ of dNTPs (10 mM), $2 \mu \mathrm{L}$ of $\mathrm{MgCl}_{2}(50 \mathrm{mM}), 2 \mu \mathrm{L}$ of each primer $(10 \mathrm{pmol})$, and $1 \mathrm{U}$ of pfu DNA polymerase (Fermentas). Amplification was performed by Hot Start at $95^{\circ} \mathrm{C}$ for $3 \mathrm{~min}$, followed by 35 cycles of denaturation at $94^{\circ} \mathrm{C}$ for $10 \mathrm{sec}$, annealing at $50^{\circ} \mathrm{C}$ for $15 \mathrm{sec}$, extension at $72^{\circ} \mathrm{C}$ for $90 \mathrm{sec}$, and $10 \mathrm{~min}$ at $72^{\circ} \mathrm{C}$ for final extension. The PCR product was recovered from the gel and purified with a high pure PCR product purification kit (Fermentas) according to the manufacturer's recommendations.
3.4. Cloning, Construction of the Recombinant Protein and Sequence Analysis

The PCR product was digested with NcoI and XbaI and ligated into pBAD that had been digested by the same enzymes, which provided 6 His residues at the N-terminus of the expressed protein. The ligations were performed with T4 DNA ligase. The ligation mixtures were transformed into competent E. coli TOP10 by the $\mathrm{CaCl}_{2}$ method. The transformed bacteria were cultured on LB agar containing $50 \mu \mathrm{g} / \mathrm{mL}$ of ampicillin, and selected colonies were analyzed to present the construct by PCR and restriction enzyme digestion. Finally, the sequencing of the constructed plasmid was performed by specific $\mathrm{PBAD}$ universal primers.

\subsection{Expression of the Truncated Gene and Purifica- tion of the Recombinant Protein}

Recombinant E. coli TOP10 cells were grown overnight in a Luria broth (LB) medium containing ampicillin $(50 \mu \mathrm{g} / \mathrm{mL})$ at $37^{\circ} \mathrm{C}$. On the following day, $50 \mathrm{~mL}$ of the LB medium was inoculated with $0.5 \mathrm{~mL}$ of the overnight culture of TOP10. The inoculated culture was grown by agitation under aerobic conditions at $37^{\circ} \mathrm{C}$ to an $\mathrm{A} 650$ of 0.5 - 0.6. Then, the expression of the cloned gene was induced by different concentrations of Arabinose (final concentration 0.02\% - 20\%). After incubation for 4 hours, the cells were harvested by centrifugation at $4^{\circ} \mathrm{C}$ and were stored at $-20^{\circ} \mathrm{C}$ until further use. Protein was expressed and purified by using the $\mathrm{Ni}$ NTA column (Qiagen) under native conditions according to the manufacturer's instructions. The quality and quantity of the purified recombinant PD was analyzed on a 15\% SDS-PAGE gel electrophoresis by the Bradford method.

\subsection{SDS-PAGE and Western Blot}

The expression of the proteins was analyzed by SDSPAGE. The bacterial pellets were suspended in a loading buffer, heated for 5 minutes at $95^{\circ} \mathrm{C}$, and $25 \mu \mathrm{L}$ of each sample was subjected to $15 \%$ SDS-PAGE gel. For the western blot, the samples were separated by the SDS-PAGE and transferred in nitrocellulose membranes by using a liquid transfer system (Bio-Rad). The membranes were blocked with skimmed milk in phosphate buffered saline (PBST) (PBS 1\% + Tween 20) and then washed several times with PBST. The membranes were incubated with the conjugated His-tag antibody (Roche) for 1 hour at room temperature and developed by Diaminobenzidine (DAB) solution (Roche, Germany).

\section{Results}

\subsection{In Silico Design}

Multiple sequencing alignments of the $h p d$ gene among the H. influenzae sequence in the GenBank showed 90\% homology. The results of mouse B cell epitope prediction showed that the peptides were located in the highly con- 
served area. Based on the alignment and epitope prediction results, the amino acids 192 to 299 formed the truncated form. The structure Z-score and the Ramachandran Z-score of the truncated PD structure were 3.38 and $98 \%$, respectively. The Z-score indicated that it was in the range of native conformations, and the plot showed that the structure was within the range of scores, typically found for native proteins of a similar size (Figure 1).

Figure 1. Results of in Silico Studies
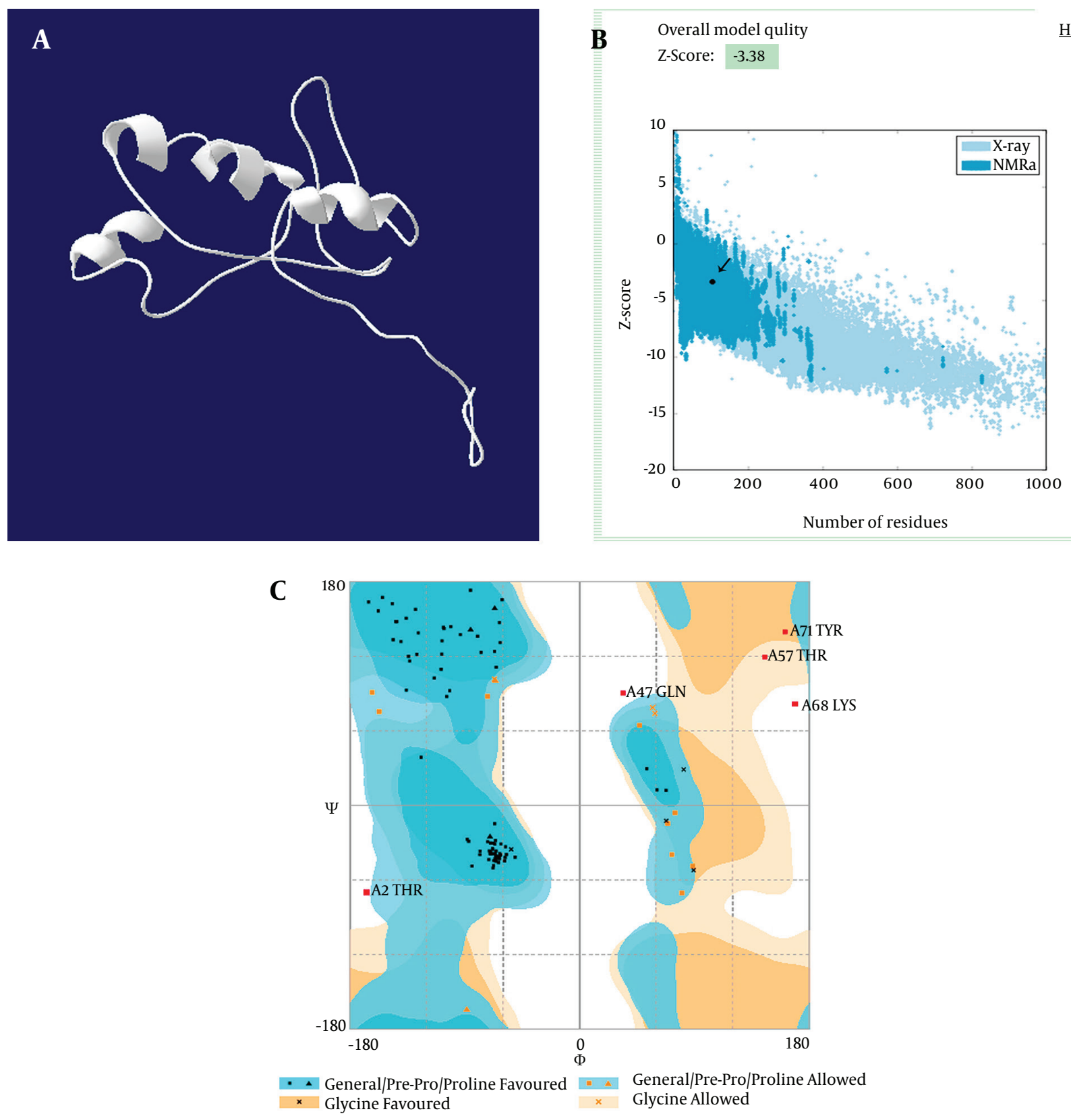

\begin{tabular}{lr} 
Number of residues in favoured region & $(\sim 98.0 \%$ expected : 86 \\
Number of residues in allowed region & $(\sim 2.0 \%$ expected : 14 \\
Number of residues in outlier region & $5(4.3 \%)$ \\
\hline
\end{tabular}

Showing (a)truncated protein D (aa 192-299) structure prediction by I-TASSER server. (b) The Z-score plot of the truncated protein D shows that the structure is within the range of scores typically found for native proteins. (c) The Ramachandran plot of the truncated protein D shows that the protein structure has $100 \%$ of its residues in most favored areas, resulting in Z-scores. 


\subsection{Amplification of the Truncated Protein D and Construction of the pBAD-Truncated Protein D}

The PCR conditions were optimized for amplification of truncated hpd gene. Electrophoresis of PCR products showed that the length of PCR fragment of truncated hpd gene was approximately 345 bp (Figure 4). Double digestion DNA was ligated into digested expression vector PBAD. E. coli Top10 cells, transformed with the ligation mixture. Individual colonies were screened to find if they were positive by colony PCR(Figure3). The positive colonies were picked up and purified. The restriction enzyme analysis of the plasmid DNA from the positive clones confirmed the presence of the insert (Figure 4).

\subsection{Expression of the Truncated hpd Gene Cloned and Purification of the Recombinant Protein}

The pBAD was optimized by parameters such as different concentrations of Arabinose and incubation time. Optimum expression was obtained with $0.2 \%$ Arabinose and an incubation time of 4 hours. The TOP10 cells harboring constructs were cultured at $37^{\circ} \mathrm{C}$ in the presence and absence of an inducer Arabinose. The whole-cell lysates were analyzed by $15 \%$ SDS-PAGE. One major band appeared approximately at the $16 \mathrm{kDa}$ position after Arabinose induction. The induction of the cells with

Figure 2. Electrophoresis of the Truncated hpd Polymerase Chain Reaction Product on Agarose Gel (1\%)

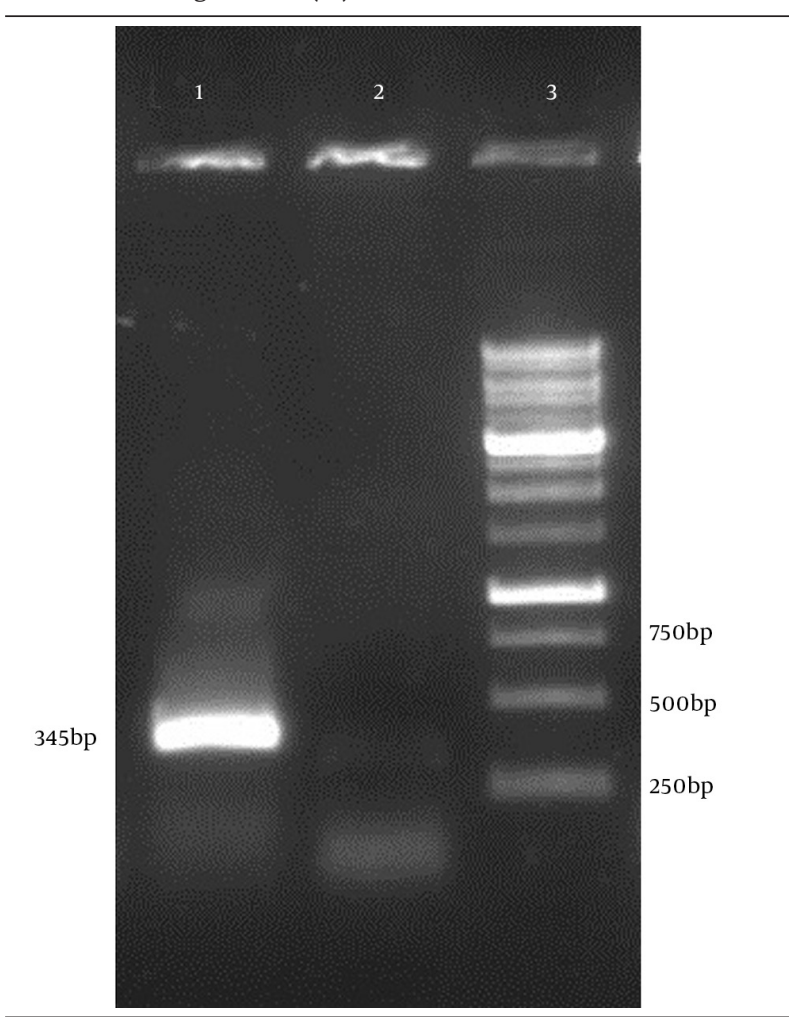

Lane 1: Single expected band of the hpd gene (345 bp), Lane 3:1kb DNA size marker.
Figure 3. Positive Colonies Screened With Colony Polymerase Chain Reaction

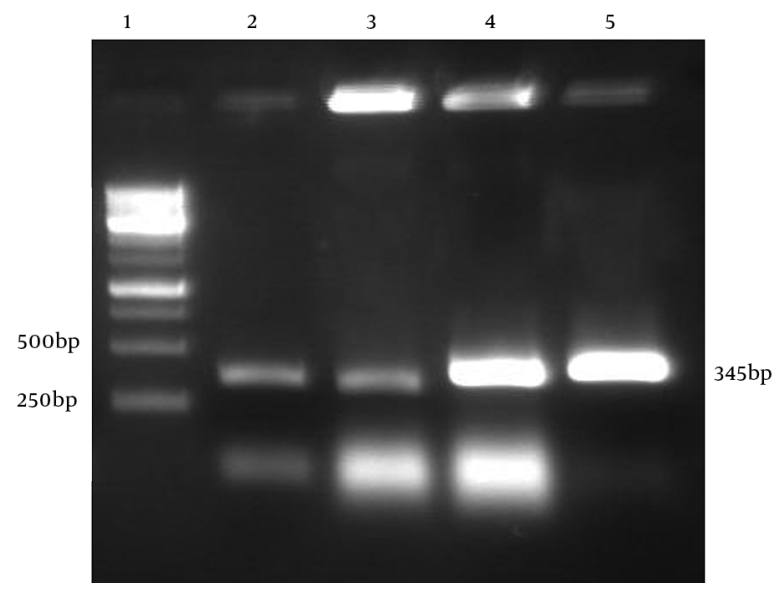

Lane 1: 1 kb DNA size marker, Lanes 2 - 5: Positive clones.

Figure 4. Electrophoresis of the Recombinant pBAD-Truncated $h p d$ on Agarose Gel (1\%)

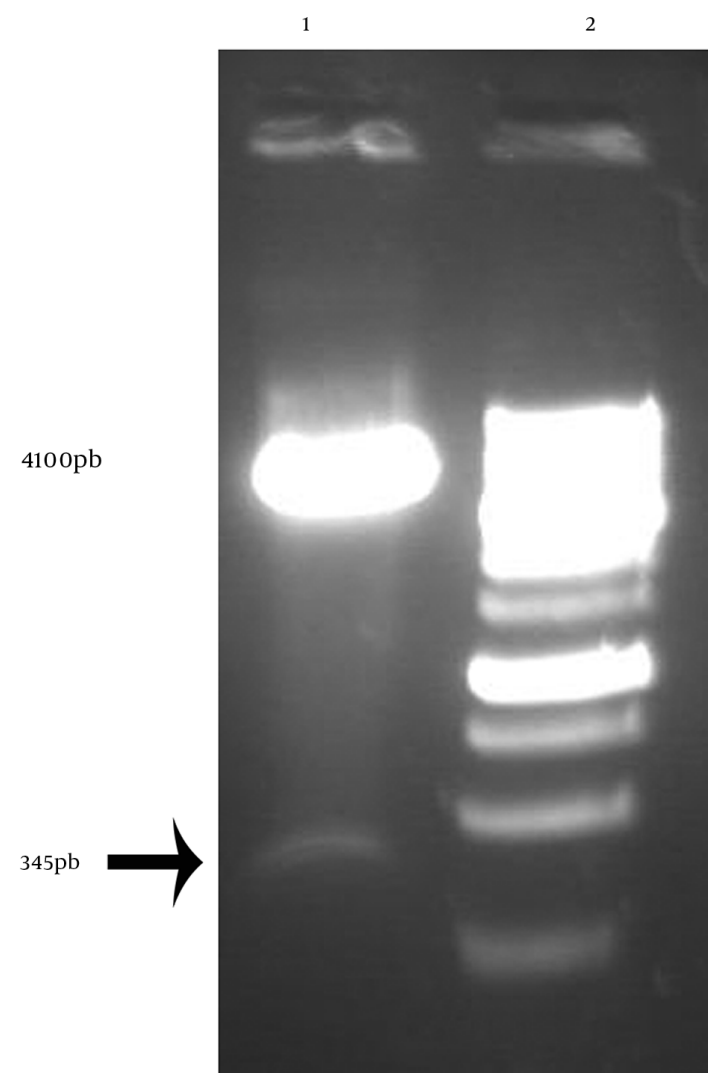

Lane 1: Double digestion of the recombinant pBAD-truncated hpd with $X b a I$ and NcoI restriction enzymes (pBAD: 4100 bp and hpd: $345 \mathrm{bp})$, Lane 2:1 kb DNA size marker. 
Arabinose $(2 \%)$ at $37^{\circ} \mathrm{C}$ for 4 hours was found to be optimal to achieve high-level expression (Figure 5).

The expressed protein was purified successfully via affinity chromatography using Ni-NTA resin HYPERLINK "http://jjmicrobiol.com/?page=article\&article_ id=10009\#figfio309" (Figure 7 ). The purification and dialysis process resulted in the yield of about $30 \mathrm{mg}$ of purified protein from $1 \mathrm{~L}$ of E. coli Top $10+$ pBAD-truncated D culture.

Figure 5. SDS-PAGE Analysis of the Recombinant Truncated Protein D With Coomassie Staining. Expression of the Truncated Protein D in TOP10 Cells was Induced.

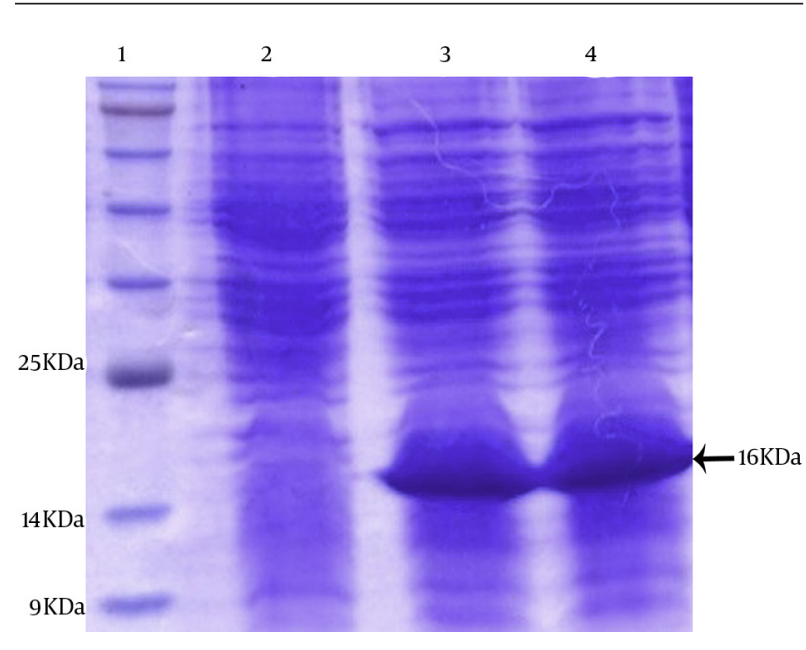

Lane 1: Protein marker, Lane 2: Non-induced with Arabinose, Lanes 3, 4: Induced with Arabinose (16 kDa).

Figure 6. SDS-PAGE Analysis of the Purified Recombinant Truncated Protein D With Coomassie Staining

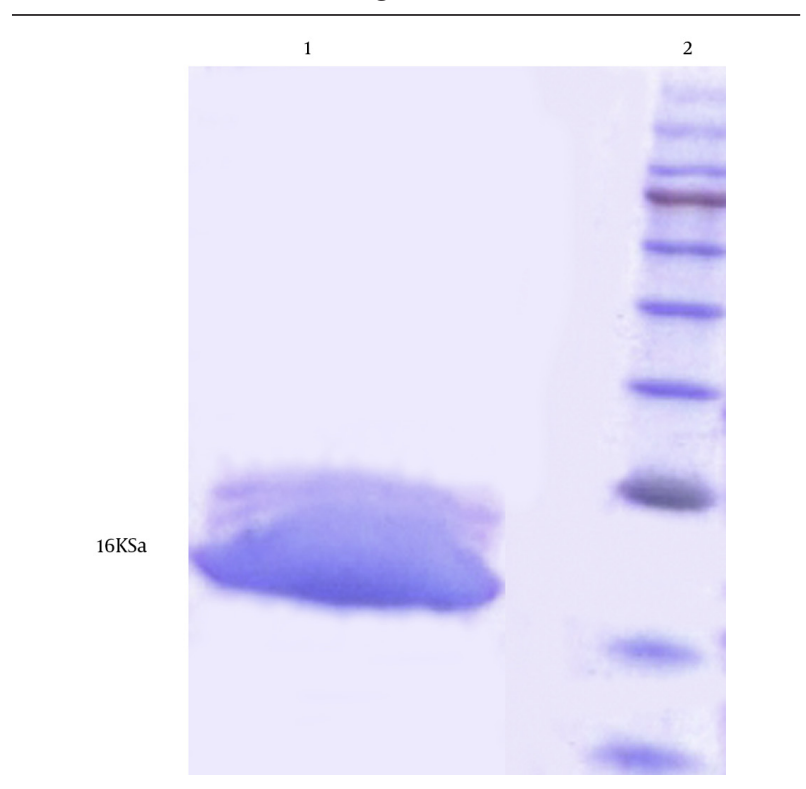

Lane 1: Recombinant truncated protein D with a molecular weight of 16 kDa, purified with Ni-NTA affinity chromatography, Lane 2: Protein marker.

\subsection{Western Blot Analysis}

The western blot analysis was performed to detect the antigenicity of the expressed protein. The $16 \mathrm{kDa}$ protein band, observed in the SDS-PAGE, was confirmed as PD by the western blot analysis using peroxidase-conjugated rabbit anti-mouse immunoglobulins (Figure 7).

Figure 7. Western Blot Analysis of the Recombinant Truncated Protein D With Peroxidase-Conjugated Rabbit Anti-Mouse Immunoglobulins (Anti-His)

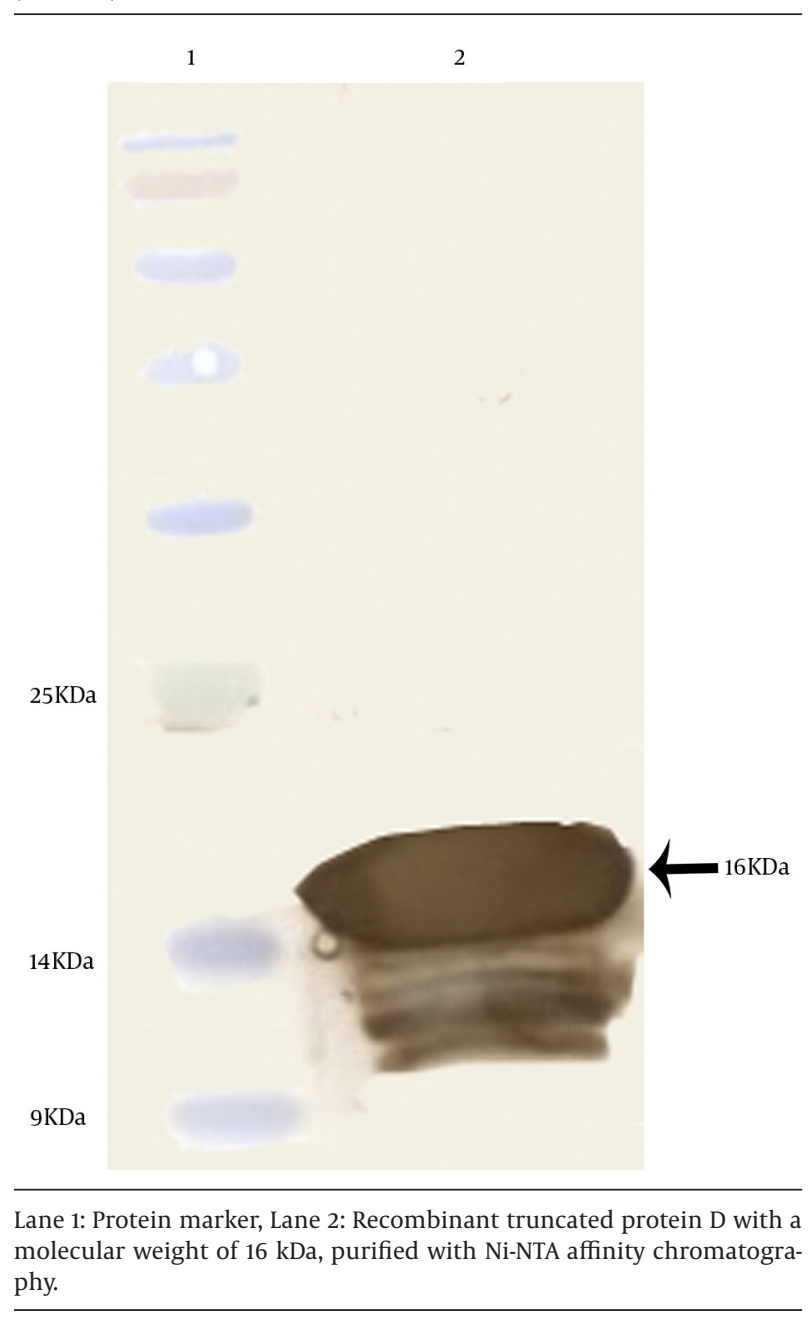

\section{Discussion}

NTHi has established itself as an important human pathogen in the past several years. Effective vaccines against the Hib strains do not protect children against infections caused by the NTHi strains (4). To develop a vaccine that protects against Hib and NTHi infections, several surface-exposed $H$. influenzae proteins have been intensely studied. Thus, the identification of immunogenic and evaluation of the immunogenicity of immunogen protein is helpful to produce effective vaccines. PD is a potential candidate for vaccine research inasmuch as a 
study showed that the sequences were $>97 \%$ identical on both the nucleotide and deduced amino acid levels (13). PD (also known as LPD) is a conserved outer-membraneassociated lipoprotein in $H$. influenzae (18). Previous studies have shown a PD-deficient mutant, constructed by linker insertion and deletion mutagenesis, to be approximately 100 -fold less virulent than its PD-expressing parental NTHi strain in inducing otitis media in an experimental rat otitis model (19). St Geme and Falkow showed that the NTHi strain lacking PD expression was less potent than the wild-type strain to cause otitis media in an experimental rat otitis model (20).

In the present study, a truncated form of PD was designed and a three-dimensional (3D)-structure protein was generated by using I-TASSER. The 3D-structure prediction for this protein and its similarity was measured by Zscores. The analysis of the protein structure showed that the 3D structure was similar to the native protein because the Z-score was in the range of native conformations. We selected the pBAD expression system because the pBAD expression vector has a signal sequence expressing proteins in periplasm (21). The recombinant truncated PD from $H$. influenzae was cloned and expressed under the control of an Arabinose promoter. The obtained results showed that the PBAD expression system was very efficient. Finally, after the optimization of expression, the yields of the expression of the recombinant proteins were $4 \mathrm{mg}$ per liter of bacterial cultures.

In conclusion, this project, for the first time, describes the construction of a genetically constructed truncated PD. Hence, further immunological studies are required to evaluate this protein as a novel and safe vaccine candidate against $H$. influenzae.

\section{Acknowledgements}

The authors would like to acknowledge all of our colleagues in the department of molecular biology, Pasture institute of Iran, who made this project possible.

\section{Authors' Contributions}

1- Study concept and design: Seyed Davar Siadat and Saeid Bouzari. 2-Acquisition of data: Ava Behrouzi. 3-Analysis and interpretation of data: Ava Behrouzi. 4- Drafting of the manuscript: Ava Behrouzi. 5- Critical revision of the manuscript for important intellectual content: Saeid Bouzari. 6- Statistical analysis: Ava Behrouzi. 7- Administrative, technical and material support: Saeid Bouzari and Seyed Davar Siadat. 8- Study supervision: Saeid Bouzari, Seyed Davar Siadat, Anis Jafari, and Shiva Irani.

\section{Funding/Support}

The project was conducted in the form of student theses.

\section{References}

1. Murphy TF, Apicella MA. Nontypable Haemophilus influenzae: a review of clinical aspects, surface antigens, and the human im mune response to infection. Rev Infect Dis. 1987;9(1):1-15.

2. Klein JO. Role of nontypeable Haemophilus influenzae in pediatric respiratory tract infections. Pediatr Infect Dis J. 1997;16(2 Suppl):S5-8.

3. Murphy TF. Respiratory infections caused by non-typeable Haemophilus influenzae. Curr Opin Infect Dis. 2003;16(2):129-34.

4. Adams WG, Deaver KA, Cochi SL, Plikaytis BD, Zell ER, Broome CV, et al. Decline of childhood Haemophilus influenzae type b (Hib) disease in the Hib vaccine era. JAMA. 1993;269(2):221-6.

5. Brinton CC, Carter MJ, Derber DB, Kar S, Kramarik JA, C. To AC, et al. Design and development of pilus vaccines for Haemophilus influenzae diseases. Pediatr Infect Dis J. 1989;8(Supplement):S62.

6. Deich RA, Anilionis A, Fulginiti J, Metcalf BJ, Quataert S, Quinn-Dey T, et al. Antigenic conservation of the 15,000-dalton outer membrane lipoprotein PCP of Haemophilus influenzae and biologic activity of anti-PCP antisera. Infect Immun. 1990;58(10):3388-93.

7. Green BA, Farley JE, Quinn-Dey T, Deich RA, Zlotnick GW. The e (P4) outer membrane protein of Haemophilus influenzae: biologic activity of anti-e serum and cloning and sequencing of the structural gene. Infect Immun. 1991;59(9):3191-8.

8. Green BA, Quinn-Dey T, Zlotnick GW. Biologic activities of antibody to a peptidoglycan-associated lipoprotein of Haemophilus influenzae against multiple clinical isolates of $\mathrm{H}$. influenzae type b. Infect Immun. 1987;55(12):2878-83.

9. van Alphen L, Caugant DA, Duim B, O'Rourke M, Bowler LD. Differences in genetic diversity of nonecapsulated Haemophilus influenzae from various diseases. Microbiology.1997;143 ( Pt 4):1423-31.

10. Badr WH, Loghmanee D, Karalus RJ, Murphy TF, Thanavala Y. Immunization of mice with P6 of nontypeable Haemophilus influenzae: kinetics of the antibody response and IgG subclasses. Vaccine. 1999;18(1-2):29-37.

11. Gu XX, Sun J, Jin S, Barenkamp SJ, Lim DJ, Robbins JB, et al. Detoxi fied lipooligosaccharide from non-typeable Haemophilus influenzae conjugated to proteins confers protection against otitis media in chinchillas. Infect Immun. 1977;65:4488-93.

12. Kyd JM, Cripps AW. Potential of a novel protein, OMP26, from nontypeable Haemophilus influenzae to enhance pulmonary clearance in a rat model. Infect Immun. 1998;66(5):2272-8.

13. Duim B, Ruiter P, Bowler LD, Dankert J, van Alphen L. Sequence variation in the hpd gene of nonencapsulated Haemophilus influenzae isolated from patients with chronic bronchitis. Gene. 1997;191(1):57-60.

14. Munson RSJ, Sasaki K. Protein D, a putative immunoglobulin D-binding protein produced by Haemophilus influenzae, is glycerophosphodiester phosphodiesterase. J Bacteriol. 1993;175(14):4569-71.

15. Fan X, Goldfine H, Lysenko E, Weiser JN. The transfer of choline from the host to the bacterial cell surface requires glpQ in Haemophilus influenzae. Mol Microbiol. 2001;41(5):1029-36.

16. Forsgren A, Riesbeck K, Janson H. Protein D of Haemophilus influenzae: a protective nontypeable $H$. influenzae antigen and a carrier for pneumococcal conjugate vaccines. Clin Infect Dis. 2008;46(5):726-31.

17. Ahren IL, Janson H, Forsgren A, Riesbeck K. Protein D expression promotes the adherence and internalization of non-typeable Haemophilus influenzae into human monocytic cells. Microb Pathog. 2001;31(3):151-8.

18. Janson H, Heden LO, Forsgren A. Protein D, the immunoglobulin D-binding protein of Haemophilus influenzae, is a lipoprotein. Infect Immun. 1992;60(4):1336-42.

19. Janson H, Melhus A, Hermansson A, Forsgren A. Protein D, the glycerophosphodiester phosphodiesterase from Haemophilus influenzae with affinity for human immunoglobulin D, influences virulence in a rat otitis model. Infect Immun. 1994;62(11):4848-54.

20. St Geme JW, Falkow S. Haemophilus influenzae adheres to and enters cultured human epithelial cells. Infect Immun. 1990;58(12):4036-44.

21. Sorensen HP, Mortensen KK. Advanced genetic strategies for recombinant protein expression in Escherichia coli. J Biotechnol. 2005;115(2):113-28. 